\title{
Metáforas nos processos de neologia da língua Suruí-Aikewára
}

\author{
Metaphors in the processes \\ of neology of the Suruí-Aikewára language \\ Jorge Domingues Lopes ${ }^{1}$ \\ Ikatu Santos Suruí ${ }^{2}$ \\ Tymykong Suruí ${ }^{3}$ \\ Eliete de Jesus Bararuá Solano ${ }^{4}$
}

\begin{abstract}
Resumo
Este artigo apresenta uma análise linguística de metáforas nos processos criativos de neologismo pelos Suruí-Aikewára, falantes da língua conhecida também por SuruíAikewára (Família Linguística Tupí-Guaraní, Tronco Tupí). Focalizamos os modos pelos quais eles constroem significações lexicais/conceptuais para topônimos, animais e coisas, que foram introduzidos em sua cultura, devido ao contato com outras sociedades. O estudo fundamenta-se, principalmente, nos trabalhos de Guilbert (1975), Lakoff \& Jonhson (1980, 2012), Lopes (2014) e nas pesquisas de campo de Cabral, Lopes e Solano (2012, 2013). O estudo também visa demonstrar que o processo criativo da metáfora, nas sociedades indígenas, envolve conceitos linguísticos embasados ou "mergulhados" em um contexto léxico/conceptual interpretativo de uma realidade sociocultural vivenciada em um dado contexto sociohistórico, pela comunidade indígena.
\end{abstract}

Palavras-chave: Família Linguística Tupí-Guaraní. Metáfora. Neologismo.

\begin{abstract}
This article presents a linguistic analysis of metaphors in the processes of creative neologismes by the Suruí-Aikewára Indians, speakers of a language also known as SuruíAikewára (Tupí-Guaraní linguistic family, Tupian stock). We focus on the ways by means of which the Suruí built lexical/conceptual meanings of toponimus, animals and things, which have been introduced in their culture through contact with other societies. The study is mainly based on the works by Guilbert (1975), Lakoff \& Jonhson (1980, 2012), Lopes (2014), as well as on fieldworks by Cabral, Lopes and Solano (2012, 2013). It also aims

\footnotetext{
${ }^{1}$ Professor Adjunto da Universidade Federal do Pará (UFPA), Campus Universitário do Tocantins/Cametá, pesquisador associado ao LALLI-UnB.

${ }^{2}$ Professor de língua Suruí na Escola Sawarapy (T.I. Sororó).

${ }^{3}$ Professora de língua Suruí na Escola Sawarapy (T.I. Sororó) e graduanda da Licenciatura Intercultural Indígena da UEPA.

${ }^{4}$ Professora Adjunta da Universidade do Estado do Pará (UEPA), pesquisadora associada ao LALLI-UnB.
} 
at demonstrating that metaphor creative process in Indigenous societies involves linguistic concepts based or 'dipped' in a lexicon-conceptual context interpretative of a sociocultural reality experienced in a certain socio-historical context by the Indigenous community.

Keywords: Tupí-Guaraní linguistic family. Metaphor. Neology.

\section{Introdução}

Neste artigo apresentamos uma análise linguística das metáforas nos processos de neologia na língua Suruí-Aikewára.

A língua Suruí-Aikewára, também denominada Suruí do Tocantins ou Mudjtíre, foi classificada por Rodrigues (1985) como pertencente ao Subconjunto IV da família linguística Tupí-Guaraní (que é uma das dez famílias que compõem o tronco linguístico Tupí). Esse povo soma uma população aproximada de 400 pessoas (cf. Lopes 2014;47) e habita a Terra Indígena Apekuokawera (mais conhecida pelo antigo nome de T.I. Sororó), localizada entre os municípios de São Domingos do Araguaia, Brejo Grande do Araguaia e São Geraldo do Araguaia, no Estado do Pará.

Para esse estudo, foi considerado o processo criativo do modo como os falantes da língua Suruí-Aikewára constroem significações lexicais/conceptuais para topônimos, animais e coisas, que foram introduzidos em sua cultura e que, por não terem lexias próprias, foram metaforizados a partir de padrões linguísticos que governam a criação e a interpretação, na mesma abordagem defendida em Moura (2002a, 2002b, 2005, 2006), que nos mostra que "a força cognitiva da metáfora está em garimpar no velho (paradigmas e sintagmas prédefinidos) o novo (a carga cognitiva de uma metáfora)" (Moura 2007: 418).

Os estudos de Lakoff (1987) e Lakoff \& Johnson (1980; 2002) sobre metáforas demonstram que a metáfora em si é corporificada por estar enraizada na percepção humana do ambiente e por interagir com o conhecimento de nossos corpos desde o início de nossa vida terrena. Se considerarmos sociedades indígenas como a Suruí-Aikewára, verificaremos que essa corporificação da metáfora faz parte de sua forma de entender e classificar as coisas existentes em seu mundo (gravidade, ligação e movimento, etc.). Tomemos como exemplo a formação de nomes próprios, em Suruí Aikewára:

Amonete $($ amon $=$ 'chuva' $+\varepsilon t \varepsilon=$ 'genuíno/verdadeiro' $=$ chuva forte $)$

Ywykatu (iwi = 'terra/chão' + katu = 'bom' = terra boa $)$

Tymykong (timi= 'bacia'+ koy = 'osso' = osso da bacia)

Wyratinga (wira $=$ 'pássaro' + tina $=$ 'branco' $=$ pássaro branco $=$ garça $)$

A metáfora não integra apenas a linguagem, conforme demonstra Lakoff (1987), mas ela tambémé constitutiva da conceituação, por essarazãodesempenha um papel cognitivo fundamental na definição das realidades cotidianas. Eis a 
razão de Lakoff (idem) apresentar muitos exemplos transculturais de sistemas classificatórios, como forma de fundamentar que a metáfora é, assim, tanto "experimentada" (ou seja, subjetiva) quanto "imaginativa" (ou seja, criativa). Sendo essas duas características que permitem muitos conhecimentos culturalmente diferenciados da realidade perceptível, em oposição à ideia objetivista de uma única e verdadeira realidade (cf. Passes 2006).

Ao analisar um conjunto de dados lexicais da língua Suruí-Aikewára, objetivou-se estabelecer um subconjunto desses dados com características bastante similares, considerando-se que 1) esse material lexical teria surgido em um período bem específico, após a situação de contato, principalmente com os não indígenas falantes do Português, ocorrida em meados do século XX, na região próxima aos rios Tocantins e Araguaia, ${ }^{5} 2$ ) esses dados manifestam uma atitude linguística conservadora dos Suruí frente aos novos elementos advindos de um mundo exterior ao seu.

Nesse sentido, apreenderam as novas referências que lhes foram sendo apresentadas nomeando-as, garantindo-lhes, assim, um lugar no conjunto léxico-semântico de sua língua. Essa nomeação pode não significar apenas "rotular" um objeto a mais no mundo, e sim aproximar o objeto ao próprio conhecimento dos falantes, tornando-o, em alguma medida, familiar a eles.

A consequência desse ato coletivo e intencional de nomear manifesta-se nas próprias estratégias linguísticas usadas pelos falantes da língua, que precisam interpretar o que não fazia parte de seu universo, a partir de suas próprias referências léxico-semântico-culturais e de seus mecanismos linguísticos, como o da metáfora.

Os dados desse subconjunto do corpus relacionam-se a elementos de diferentes domínios, sendo os principais deles: topônimos, animais e coisas. Como vimos anteriormente, alguns dos elementos relacionados a esses domínios só passaram a ser conhecidos pelos Suruí-Aikewára após o contato, o que motivou, em alguma medida, a criação de novos itens lexicais ou de novos usos e sentidos de elementos já existentes no léxico da sua língua. Logo, uma primeira definição necessária para compreender esse conjunto de dados seria a de neologia.

À semelhança de muitos povos do mundo, os Suruí-Aikewára vêm de uma tradição eminentemente oral, ${ }^{6}$ e foi neste plano que ocorreu a introdução de

\footnotetext{
${ }^{5}$ Cf. Laraia e Matta (1967, p. 28-30; 1978, p. 63-66); Ferraz (1985, p. 103-104).

${ }^{6}$ Apesar de os primeiros registros escritos dessa língua datarem de meados da década de $1980 \mathrm{com}$ as iniciativas do Conselho Indigenista Missionário (CIMI), da pesquisadora Ruth Monserrat, do Museu Nacional do Rio de Janeiro, e dos Graham, ligados ao Summer Institute of Linguistics (SIL), o ensino sistemático da escrito tem poucos anos e ainda está bem restrito ao contexto formal da escola, ou seja, principalmente aos integrantes mais jovens da comunidade.
} 
novos itens lexicais, ou seja, por meio de processos de neologia, que podem ser divididos, segundo Dubois (2002:322), em dois grandes grupos, o da neologia de forma e o da neologia de sentido

A neologia de forma consiste em fabricar por esse fazer novas unidades; a neologia de sentido consiste em empregar um significante já existente na língua considerada, conferindo-lhe um conteúdo que ela não tinha até então - que esse conteúdo seja conceptualmente novo ou que ele tenha estado até então expresso por outro significante. (Dubois 2002: 322, tradução nossa)

Tais aspectos da neologia podem ser identificados no conjunto de dados da língua Suruí-Aikewára. A título de exemplo, a neologia relacionada à forma pode ser identificada em ikomyru 'sutiã dela' e iapyakwara'yma'e 'lanterna dele'; já a neologia de sentido, pode ser identificada nos dados so kytykawa 'ralador de castanha' $\rightarrow$ 'liquidificador', ' e tukurupipina 'grilo' $\rightarrow$ 'moto'.

Observando esses dados iniciais, é possível perceber que a neologia, apesar de ser um processo baseado com frequência em conteúdos de natureza denotativa, não raras vezes faz uso de conteúdos de base metafórica.

Nesse sentido, vimos, por exemplo, que os Suruí-Aikewára, ao selecionarem os itens moj 'cobra' e kyse 'faca' para formar moj kyse 'tratar', fizeram uso metafórico da linguagem. ${ }^{8}$

Logo, descrever os processos de construção de neologismos pode ser útil para evidenciar a relação entre neologia e metáfora. Assim, baseados na tipologia de neologismos proposta por Guilbert (1975: 17-24) - neologia fonológica, sintática, semântica, além da neologia por empréstimo - buscamos analisar os neologismos da língua Suruí-Aikewára.

\section{Tipos de neologia}

A neologia, segundo Gilbert (1973:18), deve ser apreendida em sua dupla face (significante-significado) e subordina-se à lógica de funcionamento da língua em que surge, sendo que sua criação está baseada na relação entre elementos mais simples da língua. Com base nesses princípios, o referido autor propõe uma tipologia fundada na fonologia, na sintaxe e na semântica, e ainda inclui os empréstimos linguísticos.

A primeira categoria a ser analisada é a fonológica, cuja ocorrência é,

\footnotetext{
${ }^{7}$ Tradicionalmente, o tronco da paxiúba desempenhava a função de ralador da castanha e, por extensão, passou a designar o objeto que o substituiu, ou seja, o liquidificador.

${ }^{8}$ Os Suruí-Aikewára, na incerteza da origem do termo moj kyse, dão as seguintes explicações: a de que o trator deixa rastro ao passar (como a cobra) e é capaz de cortar (como a faca); a segunda, de que, ao abrir caminhos na floresta, o trator, além de cortar o mato, cortava também as cobras que nele se encontravam, ou seja, o trator seria um "cortador de cobra".
} 
segundo o autor, bastante rara, uma vez que requer um material fonológico inédito associado a uma significação igualmente inédita, tal como ocorre com "O conjunto de formações onomatopaicas que passam para uma forma linguística arbitrária os barulhos naturais ou os gritos dos seres animados é bastante reduzido" (Gilbert 1973: 19). Proporcionalmente, foi exatamente esse tipo de neologia o menos encontrado no corpus da língua Suruí-Aikewára analisado neste trabalho, isto é, encontramos apenas um dado de neologia fonológica que pode ser classificado nesse grupo. Nesse dado, a natureza onomatopaica da construção é garantida pela reduplicação da base:

\section{$1 \quad$ kitikiti}

kiti-kiti- $\varnothing$

riscar (cortando)-RED-ARG ${ }^{9}$

'risca-risca' $=$ 'serrote de carpinteiro'

Outra categoria de neologia a ser destacada é a morfológica, da qual encontramos alguns dados no corpus analisado. Essa categoria reúne, de acordo com Guilbert (1975:19), as "combinações de elementos preexistentes na língua" (tradução nossa), podendo-se dar com construções do tipo base e afixo, mas também com sentenças.

A combinação de base e sufixo é bastante comum na língua Suruí-Aikewára, como pode ser observada no seguinte dado:

\section{2 sumi'ahu}

sumi?a-hu

flauta (tipo)-INTENS

'flauta grande' = 'avião'

A base sumi'a, que é um tipo flauta fabricado pelos Suruí-Aikewára, ${ }^{10}$ se une ao sufixo intensivo - $h u$ para formar a combinação sumi'ahu, que pode ser explicada devido ao fato de o avião produzir um som que fora associado ao do instrumento musical, mas bem mais forte.

Outra combinação destacada do corpus utiliza a base misa(ra)kating 'veado fedorento' mais o sufixo -ron 'similitivo', como pode ser observado no dado 2 , a seguir:

\section{2 misakatirona \\ misakati(n)-ron-a}

\footnotetext{
${ }^{9}$ Abreviaturas: $\mathrm{ARG}=$ argumentativo; $\mathrm{INTENS}=$ intensificador; $\mathrm{RED}=$ reduplicativo; $\mathrm{SML}=$ similitivo; NMLZ=nominalizador

${ }^{10} \mathrm{O}$ povo Suruí-Aikewára ainda fabrica esse tipo de flauta, tamanho aproximado de meio metro, fabricada com bambu (takwara), cabaça (kuipi) e cera de sawtipyta (espécie de abelha).
} 
veado.fedorento(=burro)-SML-ARG

'parecido com um burro (veado fedorento)' = 'boi', 'vaca'

Aproveitando a construção já existente usada para designar 'burro', os Suruí-Aikewára construíram, por comparação assimilativa, a palavra para designar 'boi' e 'vaca', cuja distinção é estabelecida pelo acréscimo do sufixo.

Com um processo semelhante ao que formou misakatirona, a palavra misaron foi formada a partir da base misar 'veado' mais o sufixo sufixo similitivo -ron para designar 'cabra', 'bode' ou 'ovelha' (ver dado 3).

\section{3 misarona}

$\operatorname{misa}(\mathrm{s})$-ron-a

veado-SML-ARG

'que parece com veado' = 'cabra', 'ovelha', 'bode'

Já a neologia sintática, propriamente dita, possui como primeira perspectiva a composição, formada com base em elementos de língua(s)-fonte (como o Latim com relação ao Português), relacionados a elementos da língua em uso (formas livres ou presas de um lado e de outro), o que exige do falante um conhecimento tanto do funcionamento de cada uma dessas línguas, como das formas de relacionamento entre a língua-fonte e a língua-alvo.

Esse primeiro tipo de composição não foi identificado no corpus de nossa pesquisa, pois, no caso das línguas da família Tupí-Guaraní, em que prevalecia até meados do século XX apenas o uso da oralidade, não há como recorrer a sua(s) língua(s)-fonte. ${ }^{11}$

O segundo modelo de composição, por sua vez, se refere a "uma combinação de duas palavras autônomas com relação à função gramatical na frase" (Guilbert 1975: 19, tradução nossa). Essas combinações podem ser do tipo: verbo e substantivo; substantivo e substantivo; substantivo e adjetivo. No entanto, como na língua Suruí-Aikewára um nome pode ser determinado por outro nome, adotamos neste trabalho apenas a combinação nome e nome. ${ }^{12}$

No dado 4, há uma combinação do nome ma'e 'coisa' e do nome potaw 'cozimento':

4 ma'ea potawa

ma?c-a $\quad \varnothing$-pot-aw-a

coisa-ARG $\mathrm{R}^{1}$-ferver-NMLZ-ARG

'o instrumento de cozimento' = 'fogão'

\footnotetext{
${ }^{11}$ Os poucos registros de línguas dessa família datam do século XVI, dentre eles estão os registros da língua Tupinambá.

${ }^{12}$ Como não foram encontrados no corpus analisado dados da combinação nome e verbo, não trataremos deste par.
} 
Descreve-se com a forma genérica $m a$ 'e o objeto a partir de sua função (cozimento).

\section{5 arupo}

$\begin{array}{ll}\text { aru } & \text { po } \\ \text { perereca (esp.) } & \text { mão } \\ \text { 'mão da perereca (esp.)' = 'rastelo', 'ancinho' }\end{array}$

Já no dado 5, o nome aru 'perereca (esp.)' se junta ao nome po 'mão', para formar arupo 'ancinho, rastelo'. A seleção desses dois nomes da língua SuruíAikewára se deve à comparação entre a forma alongada dos dedos da perereca com os longos dentes do ancinho.

Outro dado dessa língua é o que combina os nomes wyrahu 'pássaro (esp.) e $t i$ 'bico':

6 wyrahua tia
wirahu-a ${ }^{13}$
ti-a
pássaro (esp.)-ARG
bico(ponta)-ARG

'bico do wyrahu' = 'tesoura'

A neologia nasce do processo descritivo-comparativo do movimento de abertura e fechamento do bico desse pássaro e o movimento de corte de uma tesoura.

No último dado da neologia por combinação de nomes, observamos o par 'ar 'dia' e kwahapar 'sabedor':

7 'ara kwahapara

?ar-a Ø-kwaha-par-a

dia-ARG $\mathrm{R}^{1}$-saber-NMLZ-ARG

'o sabedor do dia' = 'relógio' dia. ${ }^{14}$

Essa construção atribui uma qualidade ao relógio, a de ser o sabedor do

Outro tipo de neologia sintática a ser tratada neste trabalho é o da derivação sintagmática, que constrói neologismos baseados em estruturas sintáticas regulares da língua. Trata-se, dessa maneira, do tipo mais descritivo, porém não menos metafórico.

8 akuti nami pe pytukawa

akuti nami pe pituk-aw-a

cutia ouvido dentro furar-NMLZ-ARG

'[o osso] furador dentro do ouvido da cutia' = 'laranja'

\footnotetext{
${ }^{13}$ Muretama e Tymykong descrevem wyrahu como um pássaro grande que vive nas margens dos rios, semelhante a uma garça, e que tem um bico bastante comprido e grosso.

${ }^{14}$ Uma forma variante deste nome é 'ara ipituna, ou seja, 'sabedor da noite'.
} 
Essa estrutura sintagmática combina diferentes elementos para descrever o objeto que será comparado a uma parte da laranja, ou seja, o osso pontudo que fura e que fica dentro do ouvido da cutia possui uma forma próxima à da semente do fruto.

Continuando a tratar dos processos de neologia, segundo a proposta de Guilber (1975), há de se incluir o do tipo semântico, que se dá no nível dos semas e, por isso, não produz nenhuma modificação na forma da palavra. Ademais, de acordo com Guilbert (1975:21), tal significação se dá também por meio da categoria gramatical e está intimamente relacionado ao uso da língua no contexto sociocultural dos falantes.

9 so kytykawa

so kitik-aw-a

castanha ralar-NMLZ-ARG

'ralador de castanha' = 'paxiúba' = 'liquidificador'

so kytykawa 'ralador de castanha-do-pará' já existia na língua do povo SuruíAikewára e o objeto usado pelos mais velhos para essa função era um pedaço do tronco da paxiúba, que foi substituído pelo liquidificador. Por conseguinte, o novo objeto recebeu a mesma denominação do anterior, pois desempenhava a mesma função dele.

10 ma'ea kytykawa

ma? -a kitik-aw-a

coisa-ARG ralar-NMLZ-ARG

'ralador de coisa' = 'liquidificador'

Trata-se de uma forma variante, mais genérica, da anterior, que também serve para designar o aparelho elétrico que passou a ralar qualquer coisa no lugar da paxiúba.

\section{1 taratirating}

taraticatin- $\varnothing$

libélula-ARG

'libélula' = 'helicóptero'

No dado 11, há a ocorrência de uma neologia semântica ao ampliar a significação de taratirating 'libélula' para designar também 'helicóptero', cujo movimento rápido das hélices foi comparado ao movimento das asas do inseto. Do mesmo modo, observamos o resultado de uma comparação formal entre o animal já conhecido pelo povo e um novo objeto introduzido na cultura SuruíAikewára. 


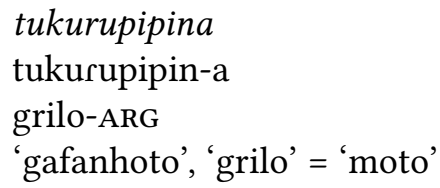

O último tipo de neologia a ser destacado é o da neologia por empréstimo. Relativamente comum em contextos de contato linguístico, trata-se de um processo em que uma palavra é retirada de seu ambiente linguístico original e é transferida para o novo ambiente, adaptando-se, em geral, as características fonéticas e morfológicas da língua-alvo.

No contexto da língua Suruí-Aikewára, o maior contato se deu com o Português e, por isso, foi dele que muitos empréstimos foram tomados. ${ }^{15}$

\section{Perẽj

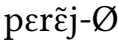 \\ Belém-ARG \\ 'Belém' = '(cidade de) Belém (do Pará)'}

Trata-se de um topônimo usado em Português e que passou por uma adaptação fonética para a língua Suruí-Aikewára, ou seja, ocorreu o ensurdecimento da consoante inicial e a mudança da consoante tepe pela aproximante lateral alveolar na sílaba tônica, haja vista não existirem as consoantes $[\mathrm{b}]$ e $[\mathrm{r}]$ nessa língua indígena.

\section{À guisa de conclusão}

Identificamos ao longo da pesquisa que fundamentou neste estudo, aspectos da percepção do povo Suruí Aikewára do seu ambiente de vida ao nomear elementos culturais emprestados. Essa nomeação é construída, segundo sua experiência linguística e cultural, o que é referendado pelo fato das traduções dos empréstimos do Português, terem sido feitas pelos próprios falantes da língua, em especial Ikatu e Tymykong, - professores de língua Suruí-Aikewára na Escola Sawarapy -, em vários momentos de pesquisa de campo; são dados que ratificam, assim, os processos de neologia pelos quais a língua Suruí-Aikewára vem passando de forma conservadora, ao buscarem entender e classificar as novas coisas existentes que adentram seu mundo a partir do léxico de sua própria língua. Isso demonstra que, mesmo em situação de vulnerabilidade

${ }^{15} \mathrm{O}$ contato com o português, que foi introduzida na comunidade Suruí-Aikewára logo após o contato em meados do século XX, foi decisivo para a mudança de uma situação de monolinguismo para a de bilinguismo, cujo resultado foi a prevalência da língua neolatina sobre a língua da família Tupí-Guaraní. Hoje, o número de falantes da língua SuruíAikewára é bastante reduzido e, entre as mais novas gerações, predomina o uso exclusivo do Português. 
linguística, esse povo, assim como muitos outros no mundo, busca estratégias de manutenção de seu conhecimento, de sua história e de seu mundo, ao adotar elementos culturais de outras culturas.

\section{Referências}

Dubois, Jean et al. 2002. Dictionnaire de linguistique. Paris, França: Larousse-Bordas.

Ferraz, Iara. Suruí. 1985. In: Carlos Alberto Ricardo (Coord.). Povos indígenas no Brasil: Sudeste do Pará (Tocantins). São Paulo: CEDI, pp. 100-121. Vol. 8.

Guilbert, Louis. 1975. La créativité lexical. Paris, França: Larousse. (Coleção Langue et Langage)

Lakoff, George 1987. Women, Fire and Dangerous Things. Chicago, University of Chicago Press.

Lakoff, G.; M. Johnson. 1980. Metaphors we live by. Chicago: Chicago University Press.

2002. Metáforas da vida cotidiana. Tradução de M. S. Zanotto e V. Maluf. São Paulo: EDUC.

Laraia, Roque de Barros; Roberto da Matta. 1967. Índios e castanheiros: a emprêsa extrativista e os índios no médio Tocantins. São Paulo: Difusão Européia do Livro. (Coleção Corpo e Alma do Brasil; XXI)

Lopes, J. D. 2014. Uma interface da documentação linguística e modelos lexicográficos para línguas indígenas brasileiras: uma proposta para o Suruí-Aikewára. Tese (Doutorado em Linguística), Instituto de Letras da Universidade de Brasília, Brasília, DF. 599p.

Moura, Heronides. 2002a. Lexicon and context in the production of meaning. Révue de sémantique et pragmatique 12:17-35.

. 2002b. Linguagem e cognição na interpretação de metáforas. Revista Veredas 6(1):153-161.

. 2005. Metáfora: das palavras aos conceitos. Letras de Hoje 40(139): 20-45.

.2006. The conceptual and the linguistic factors in the use of metaphors. DELTA 22 (n. especial):81-94.

. 2007. Relações paradigmáticas e sintagmáticas na interpretação de metáforas. Linguagem em (Dis)curso 7(3):417-452.

Passes, Alan. 2006. Do um à metáfora. Para um entendimento da matemática pa'ikwené. Revista de Antropologia 49(1). São Paulo, USP.

Rodrigues, Aryon D. 1985. Relações internas na família lingüística Tupí-Guaraní. Revista de Antropologia 27/28:33-53. São Paulo.

Data recebimento: 23/04/2015

Data aceite: 15/07/2015 